\title{
An observational analysis of meal patterns in overweight and obese pregnancy: exploring meal pattern behaviours and the association with maternal and fetal health measures
}

\author{
Kate M. Ainscough ${ }^{1} \cdot$ Maria A. Kennelly ${ }^{1} \cdot$ Karen L. Lindsay $^{1} \cdot$ Eileen C. O'Brien ${ }^{1}$ - Elizabeth J. O'Sullivan ${ }^{1,2}$. \\ John Mehegan ${ }^{3}$ - Eileen R. Gibney ${ }^{4}$ - Fionnuala M. McAuliffe ${ }^{1}$ (i)
}

Received: 15 March 2019 / Accepted: 9 September 2019 / Published online: 15 November 2019

(C) The Author(s) 2019

\begin{abstract}
Background Nutrient intakes are known to be poorer among pregnant women with raised body mass index (BMI) than those with a healthy BMI. While meal patterns have the potential to influence obstetric, metabolic and anthropometric measures for mother and infant, limited data exists regarding meal patterns among pregnant women with raised BMI.

Aim To identify categories of meal patterns among pregnant women with overweight and obesity and determine whether patterns change with advancing gestation. To determine if maternal meal patterns are associated with dietary intakes and pregnancy outcomes.

Methods Prospective, observational analysis of pregnant women $(n=143)$ (BMI $25-39.9 \mathrm{~kg} / \mathrm{m}^{2}$ ). Meal pattern data were analysed from 3-day food diaries at 16 and 28 weeks' gestation. Outcomes include maternal blood glucose, insulin resistance, gestational diabetes, gestational weight gain and infant anthropometry.

Results Three meal pattern categories were identified: 'main meal dominant' ( 3 main eating occasions $+0-3$ snacks), 'large meal dominant' ( $\leq 2$ main eating occasions $+<2$ snacks), and 'snack dominant' ( 3 main eating occasions $+>3$ snacks and $\leq 2$ main + $\geq 2$ snacks). A main meal-dominant pattern prevailed at 16 weeks' (85.3\%) and a snack-dominant pattern at 28 weeks' (68.5\%). Dietary glycaemic index was lower among the main meal versus large meal-dominant pattern at 28 weeks $(P=0.018)$. Infant birth weight $(\mathrm{kg})$ and macrosomia were highest among participants with a large meal-dominant pattern at 28 weeks $(P=0.030$ and $P=0.008$, respectively).

Conclusion Women with raised BMI changed eating patterns as pregnancy progressed, moving from main meal-dominant to snack-dominant patterns. Large meal-dominant meal patterns in later pregnancy were associated with higher glycaemic index and greater prevalence of macrosomia.
\end{abstract}

Keywords Dietary glycaemic index · Infant birth weight · Maternal diet · Meal pattern behaviour · Overweight and obese pregnancy

Fionnuala M. McAuliffe

fionnuala.mcauliffe@ucd.ie

1 UCD Perinatal Research Centre, Obstetrics \& Gynaecology, School of Medicine, National Maternity Hospital, University College Dublin, Dublin, Ireland

2 Present address: School of Biological and Health Sciences, Technological University Dublin, Dublin, Ireland

3 UCD School of Public Health, Physiotherapy and Sports Science, University College Dublin, Dublin, Ireland

4 UCD Institute of Food and Health, School of Agriculture and Food Science, University College Dublin, Dublin, Ireland

\section{Introduction}

Guidelines on healthy eating provided to pregnant women reflect national dietary recommendations and provide information specific to macronutrients and micronutrients of importance during pregnancy [1-4]. In pregnancies complicated by gestational diabetes mellitus (GDM), more specific dietary and lifestyle guidance is used as a method of treatment [5-8], including advice to improve glycaemic control through portion control, eating at regular intervals, and reducing dietary glycaemic index (GI) and glycaemic load (GL). In the absence of GDM, dietary information provided routinely in clinical practise contains no formal recommendations for meal 
patterns during pregnancy. The Institute of Medicine (IOM) suggests eating small to 'moderate-sized meals at regular intervals, and eating nutritious snacks' [1] during pregnancy. Thus, given that pregnancy is an altered metabolic state [9], examining maternal meal patterns to provide a basis for advice may be of importance, particularly in overweight or obesity, to maintain glucose homeostasis.

Assessment of maternal diet to date has involved examination of nutrient intakes [10-12], dietary patterns [11, 13-15] and diet quality using scoring-based indices [16-19]. There is a dearth of evidence regarding optimal meal patterns in pregnancy, however. To date, only three studies have examined meal patterns during pregnancy [20-22]. It has been suggested that following a 'regular' meal pattern (three meals plus 2 or more snacks) results in more calories consumed and a reduced risk of pre-term delivery [21], while following a 'main meal' pattern is associated with a reduced risk of delivering pre-term [20]. Increased meal frequency has previously associated with higher 2-h post-prandial glucose, during the late-second trimester of pregnancy in a cohort of Asian women in Singapore [22]. The evidence to date suggests the potential for meal patterns to play an influential role in obstetric, metabolic and anthropometric measures for both mother and infant. However, no published studies to date have examined the relationship between maternal meal patterns and infant birth weight or gestational weight gain (GWG). Furthermore, despite our understanding that women with high body weight have poorer dietary intake and pregnancy outcomes, there is a lack of evidence regarding the way in which women with raised BMI construct their meals throughout the day. A deeper examination into their dietary patterns is warranted to understand their daily food habits. Adding evidence to this field of research could help to frame new dietary advice administered during pregnancy. This may add value to existing dietary recommendations by providing practical advice on meal and snack patterns and frequency.

The primary aim of this research is to identify categories of meal patterns and to determine whether patterns change with advancing gestation. The secondary aims of this research are to determine whether differences exist in maternal demographic profiles and nutrient intakes across meal pattern categories, and to prospectively analyse whether any relationship exists between meal patterns and maternal and infant outcomes.

\section{Methods}

\section{Study design and sample selection}

This is a prospective observational study using data from the control group of the PEARs (pregnancy exercise and nutrition with smartphone application support) randomised controlled trial $[23,24]$ carried out at The National Maternity Hospital, Dublin, Ireland, between March 2013 and February 2016. This study received ethical approval from The National Maternity Hospital Research Ethics Committee, and written informed consent was obtained from participants.

A total of 565 women aged between 18 and 45 years, with a BMI $\geq 25 \mathrm{~kg} / \mathrm{m}^{2}$ and $\leq 39.9 \mathrm{~kg} / \mathrm{m}^{2}$ and with a singleton pregnancy attending antenatal clinics were randomised in early pregnancy between 10 and 15 weeks' gestation. To assess typical meal patterns during pregnancy, data from participants randomised to the control group only $(n=287)$ were included in this analysis. The control group received no individual dietary advice, as is current practise for standard antenatal care. All women attending the hospital received a copy of the Health Service Executive's Healthy Eating in Pregnancy booklet [2] at their first hospital visit.

\section{Collection and assessment of maternal demographic data}

Education level, maternal ethnicity and parity data were collected. Socioeconomic status was assessed as a level of deprivation according to The Pobal Haase-Pratschke (HP Pobal) Deprivation Index, a neighbourhood deprivation score based on Irish census data [25].

\section{Collection and assessment of dietary data}

Dietary intakes were assessed using 3-day food diaries, completed prior to the first study visit at 16 weeks' gestation, and following the second study visit at 28 weeks' gestation. Participants completed the food diaries at home. They received written instructions that were prepared by the research dietitian and nutritionist. Two weekdays and one weekend day were included to capture meal patterns throughout the week. Nutritics ${ }^{\circledR}$ Professional Nutrition Analysis Software, version 4.267, Research Edition (Nutritics, Dublin, Ireland, www. nutritics.com) was used to assess dietary intakes. Trained research nutritionists entered food diaries. Time of day, day of the week and the type of eating occasion (breakfast, lunch, dinner or snack) were recorded. Participants provided portion sizes as household measures. Macronutrient and micronutrient composition of foods were calculated from validated food composition databases [26-28]. Mean daily macronutrient and micronutrient intakes, GI, GL and macronutrients as percentages of total energy intake were calculated.

\section{Meal pattern classification}

Eating occasions were classified as breakfast, lunch, dinner or snacks based on the time of day and/or order in which they were reported, and their composition [29], e.g. Spaghetti Bolognese considered dinner. Where time of day was not specified, the order in which an eating occasion was reported 
and its composition were used to determine the meal type, taking the structure and composition of a typical western diet into account. There is at present, no general agreement in the literature on how to distinguish snacks from main meals when not specified by participants [29]. Breakfast, lunch and dinner meal types were later collapsed into a single category, titled 'main meals' and the mean number of total eating occasions, main meals and snacks were computed. From here, meal pattern categories were derived from the data. Patterns were based on preferences for consuming main meals or snacks. Participants were considered to have a 'main meal-dominant' pattern if they had all three main meals; breakfast, lunch and dinner on average over the three days, with or without snacks, up to a maximum of three snacks ( 3 main meals $+0-3$ snacks). Participants were considered to have a 'snack-dominant' meal pattern if they consumed more snacks than main meals per day. This included those who consumed all three main meals but greater than 3 snacks ( 3 main $+>3$ snacks), and those consuming fewer than 3 main meals and 2 or more snacks ( $\leq 2$ main $+\geq 2$ snacks). The third pattern was termed the 'large meal-dominant' pattern, as participants had fewer total eating occasions per day, typically up to 2 main meals but fewer than 2 snacks ( $\leq 2$ main $+<2$ snacks).

\section{Assessment of energy under-reporting}

Energy under-reporting was assessed using the Goldberg method [30] which has been previously used among pregnant cohorts [10, 31]. Firstly, participants' basal metabolic rate (BMR) was calculated using Henry-Oxford Equations [32]. Goldberg ratios were then calculated using participant's energy intake (EI) in calories, to their BMR (EI:BMR). A Goldberg ratio of $\leq 0.9$ was used to define energy underreporting.

\section{Assessment of maternal and neonatal outcomes}

Early pregnancy weight (kilogram) was routinely recorded at the first hospital visit (between 10 and 15 weeks' gestation). Gestational weight gain was calculated as the difference between weight at initial visit and term (last recorded weight between 36 weeks' gestation and delivery). Participants were categorised as having met or exceeded IOM guidelines.

GDM was diagnosed at 28 weeks' gestation using International Association of Diabetes Pregnancy Study Group (IADPSG) criteria post $75 \mathrm{~g}$ oral glucose tolerance test [31]. Fasting insulin and c-peptide samples were analysed and HOMA2-IR was calculated [33].

Gestational age at delivery and infant birth weight $(\mathrm{kg})$ were obtained from medical records. Birth weight centiles were calculated with Gestation-Related Optimal Weight (GROW) software, version 6.7.5.1 (Gestation Network, Perinatal Institute, Birmingham, UK). Large-for-gestational- age infants were those with a birth weight $>90$ th centile. Macrosomic infants were considered those with a birth weight of $\geq 4 \mathrm{~kg}$. Pre-term was defined as delivered $<37$ weeks' gestation.

\section{Data analyses}

Of the 287 participants in the control group, 143 participants returned complete dietary data at both time points. All analyses were performed among those with dietary data at both time points. Analysis was conducted including those who were classified as under-reporters and sensitivity analysis was subsequently carried out excluding the under-reporters. Variables were visually assessed for normality using histogram outputs. Non-normally distributed variables were $\log$ transformed for analysis. Continuous data are reported as mean (SD), and categorical data are reported as $n(\%)$. Independent sample $t$ tests were used to compare meal frequencies and mean daily nutrient intakes between 16 and 28 weeks' gestation using time as the grouping variable among the whole group. Chisquared analyses were used to compare the proportion of participants within each meal pattern category between time points. In the sensitivity analysis, paired sample $t$ tests were used to compare meal frequencies and nutrient intakes, and McNemar's test compared meal pattern categories between time points. One-way analysis of variance (ANOVA) was

Table 1 Baseline characteristics for participants with complete dietary data $(n=143)$

\begin{tabular}{lll}
\hline & Mean & SD \\
\hline Age (year) & 32.10 & 3.98 \\
Early-pregnancy weight $(\mathrm{kg})$ & 79.57 & 10.59 \\
Height $(\mathrm{m})$ & 1.65 & 0.06 \\
Gestational age (weeks) & 15.64 & 1.57 \\
Early-pregnancy body mass index $\left(\mathrm{kg} / \mathrm{m}^{2}\right)$ & 29.11 & 3.22 \\
BMI category, $n(\%)$ & & \\
25.0-29.9 $\left(\mathrm{kg} / \mathrm{m}^{2}\right)$ (overweight) & 101 & 70.6 \\
30.0-39.9 $\left(\mathrm{kg} / \mathrm{m}^{2}\right)$ (obese) & 42 & 29.4 \\
Primiparous, $\mathrm{n}(\%)$ & 88 & 61.5 \\
Ethnicity, $n(\%)$ & & \\
Caucasian & 126 & 88.1 \\
Other & 17 & 11.9 \\
SES, $n(\%)$ & & \\
Advantaged & 101 & 70.6 \\
Disadvantaged & 42 & 29.4 \\
Completed 3rd-level education, $\mathrm{n}(\%)$ & 109 & 76.2 \\
Smoker, $\mathrm{n}(\%)$ & 5 & 3.6 \\
\hline
\end{tabular}

$B M I$, body mass index; SES, socioeconomic status

Values are mean SD unless otherwise indicated

SES determined by HP Pobal Deprivation Index 
used to compare maternal characteristics between meal pattern categories at both 16 and 28 weeks' gestation. Subsequently, one-way ANOVA compared macronutrient intakes and maternal and infant outcomes between meal patterns at the same intervals. Analyses were performed among the whole group, and in those in the sensitivity analysis. Post hoc tests were performed on all one-way ANOVA using Dunnett's T3 due to unequal sample sizes between meal pattern categories. Where means violated the homogeneity of variances assumption, the Welch test statistic for significance was reported. Chisquared analyses were used where maternal and infant outcomes were categorical. Bivariate associations with significance of $P<0.05$ were further analysed using multiple regression models. Models were created using a forced-enter approach and were adjusted for confounders.

IBM SPSS software for Mac version 24.0 (SPSS Inc., Chicago, IL) was used to perform all statistical analyses.

\section{Results}

\section{Study participants}

The characteristics of the cohort $(n=143)$ are listed in Table 1.

\section{Meal patterns at 16 and 28 weeks' gestation}

On average, participants had four eating occasions per day at 16 weeks' gestation and this predominantly consisted of an average of 3 main meals with 1 additional snack (Table 2). Participants increased the number of eating occasions to 4.7 at 28 weeks, with fewer main meals and more snacks. At 16 weeks', most participants had a main meal-dominant pattern but by 28 weeks', the majority were considered snack dominant (Table 2, Fig. 1). There were no differences in maternal characteristics between those within the different meal pattern categories at 16 weeks' gestation (Table 3 ). More participants with a main meal pattern at 28 weeks' gestation were primiparous compared with other meal patterns (Table 3 ).

\section{Comparison of nutrient intakes}

There were no differences in nutrient intakes between meal patterns at 16 weeks' gestation (Table 4). At 28 weeks' gestation, there was a significant difference in dietary GI $(P=$ 0.018). Those in the main meal-dominant pattern had a significantly lower GI $(55.85 \pm 4.51)$ compared with those in the large meal-dominant pattern (59.80 \pm 4.85$)$; however, dietary GI among the snack-dominant pattern did not significantly differ from other patterns.

Comparison of mean daily nutrient intakes between 16 and 28 weeks' gestation showed the percentage of energy from saturated fat was higher at 28 weeks' gestation (13.98 \pm 2.59) compared with 16 weeks' gestation $(13.24 \pm 2.98)$ $(P=0.005)$ (Table 5). The percentage of energy from carbohydrates was lower at 28 weeks' gestation than at 16 weeks' gestation $(45.17 \pm 5.50$ vs. $46.34 \pm 6.11)(P=0.031)$ (Table 5).

Table 2 Comparison of meal frequencies and meal pattern categories between 16 and 28 weeks' gestation among participants with complete dietary data $(n=143)$

\begin{tabular}{|c|c|c|c|c|c|}
\hline & \multicolumn{2}{|c|}{16 weeks $(n=143)$} & \multicolumn{2}{|c|}{28 weeks $(n=143)$} & \multirow[t]{2}{*}{$P$} \\
\hline & Mean & SD & Mean & SD & \\
\hline \multicolumn{6}{|l|}{ Meal frequencies } \\
\hline Total eating occasions & 4.04 & 1.33 & 4.67 & 1.29 & $<0.001$ \\
\hline Main meals & 2.85 & 0.24 & 2.23 & 0.36 & $<0.001$ \\
\hline Snacks & 1.18 & 1.31 & 2.45 & 1.17 & $<0.001$ \\
\hline Meal patterns categories & $n$ & $\%$ & $n$ & $\%$ & \\
\hline \multicolumn{6}{|l|}{ Main meal dominant } \\
\hline 3 main $+0-3$ snacks & 122 & 85.3 & 20 & 14.0 & $<0.001$ \\
\hline \multicolumn{6}{|l|}{ Large meal dominant } \\
\hline$\leq 2$ main $+<2$ snacks & 8 & 5.6 & 25 & 17.5 & 0.001 \\
\hline Snack dominant & 13 & 9.1 & 98 & 68.5 & $<0.001$ \\
\hline 3 main $+>3$ snacks & 8 & 5.6 & 5 & 3.5 & 0.581 \\
\hline$\leq 2$ main $+\geq 2$ snacks & 5 & 3.5 & 93 & 65.0 & $<0.001$ \\
\hline
\end{tabular}

Data are mean SD unless otherwise indicated

Where data are non-normally distributed, they were log transformed for analysis; total eating occasions, snacks

$P$ values were calculated using paired sample $t$ tests for continuous variables and McNemar's chi-squared tests for independence for categorical variables Main meals include breakfast, lunch and dinner 
Fig. 1 Proportion of participants in each meal pattern category, at both 16 and 28 weeks' gestation, and movement over time

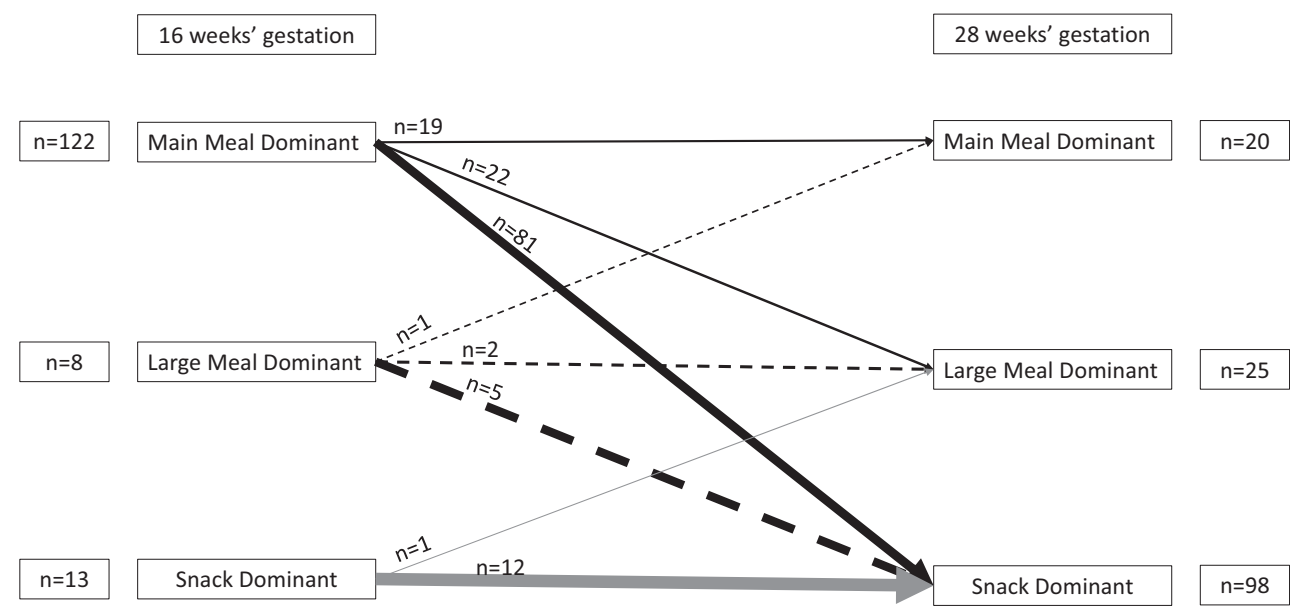

\section{Comparison of maternal and infant outcomes}

Those with a large meal-dominant pattern at 16 week's gestation had significantly lower GWG to term $(6.92 \pm 3.01)$ compared with those with a main meal $(13.10 \pm 5.10)$ or snack $(12.34 \pm 7.59)$ dominant pattern $(P=0.025)$ (Table 6$)$. No association was observed between meal patterns at 28 weeks' gestation and weight gain.
Infant birth weight $(\mathrm{kg})$ differed significantly between meal pattern categories at 28 weeks' (main meal dominant, $3.65 \pm$ 0.49 ; large meal dominant, $3.93 \pm 0.66$; and snack dominant, $3.62 \pm 0.49 ; P=0.030)$. Approximately half $(52 \%)$ of those with a large meal-dominant pattern at 28 weeks' gestation gave birth to a macrosomic infant compared with $20 \%$ in the main meal-dominant pattern and $21 \%$ in the snack-dominant pattern $(P=0.008)$ (Table 6).

Table 3 Comparison of maternal characteristics between meal pattern categories at 16 and 28 weeks' gestation among participants with complete dietary data at both time points $(n=143)$. Mean and SD are presented, unless otherwise indicated

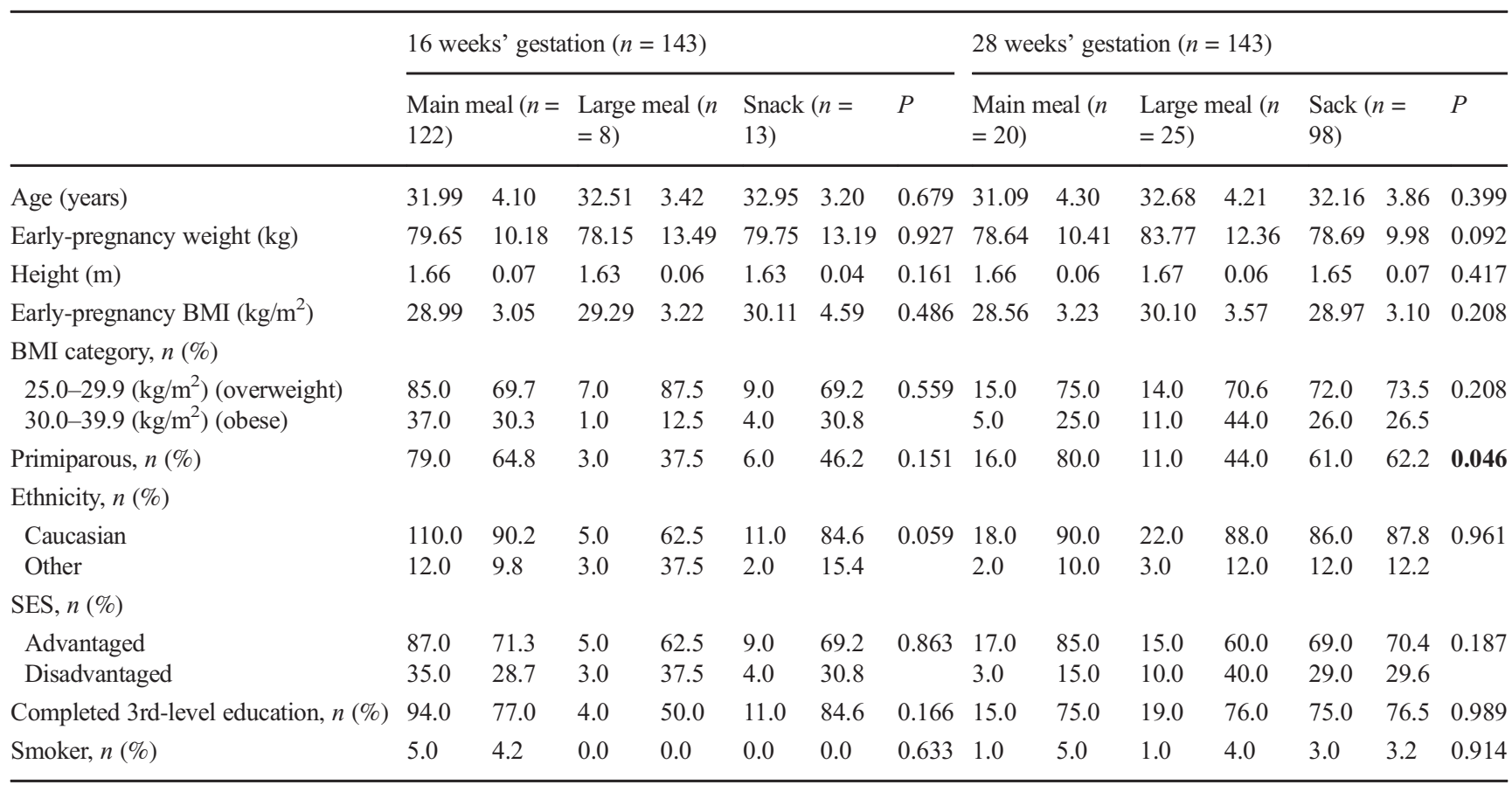

$B M I$, body mass index; $S E S$, socioeconomic status

Significance is set at alpha 0.05 using chi-squared tests for independence for categorical variables and one-way analysis of variance (ANOVA) for continuous variables using post hoc Dunnett's T3 tests for unequal sample sizes 
Table 4 Comparison of mean daily nutrient intakes between meal pattern categories at 16 and 28 weeks' gestation among participants with complete dietary data at both time points $(n=143)$. Mean and SD are presented

\begin{tabular}{|c|c|c|c|c|c|c|c|c|c|c|c|c|c|c|}
\hline & \multicolumn{6}{|c|}{16 weeks' gestation $(n=143)$} & \multicolumn{8}{|c|}{28 weeks' gestation $(n=143)$} \\
\hline & \multicolumn{2}{|c|}{$\begin{array}{l}\text { Main meal }(n= \\
122)\end{array}$} & \multicolumn{2}{|c|}{$\begin{array}{l}\text { Large meal }(n= \\
8)\end{array}$} & \multicolumn{2}{|c|}{ Snack $(n=13)$} & \multirow{2}{*}{$\begin{array}{l}P \\
0.564\end{array}$} & \multicolumn{2}{|c|}{$\begin{array}{l}\text { Main meal }(n= \\
20)\end{array}$} & \multicolumn{2}{|c|}{$\begin{array}{l}\text { Large meal }(n= \\
25)\end{array}$} & \multicolumn{2}{|c|}{ Snack $(n=98)$} & \multirow{2}{*}{$\begin{array}{l}P \\
0.538\end{array}$} \\
\hline Energy (kcal/day) & 1880.54 & 406.46 & 1719.34 & 501.26 & 1896.74 & 499.91 & & 1867.35 & 349.55 & 1786.25 & 462.46 & 1897.89 & 461.00 & \\
\hline Protein (g/day) & 79.33 & 19.10 & 65.91 & 15.49 & 86.75 & 26.33 & 0.065 & 81.06 & 13.91 & 79.90 & 23.66 & 82.40 & 20.77 & 0.851 \\
\hline$\%$ TE protein & 17.03 & 2.97 & 16.21 & 5.50 & 18.18 & 3.15 & $0.450^{1}$ & 17.66 & 3.18 & 17.87 & 2.52 & 17.57 & 3.18 & 0.905 \\
\hline $\begin{array}{l}\text { Carbohydrates } \\
\text { (g/day) }\end{array}$ & 216.49 & 52.39 & 206.45 & 70.95 & 217.49 & 42.08 & 0.868 & 207.46 & 40.37 & 197.04 & 54.45 & 215.59 & 57.19 & 0.305 \\
\hline$\%$ TE carbohydrates & 46.18 & 6.01 & 47.54 & 6.80 & 47.13 & 6.97 & 0.741 & 44.59 & 5.10 & 44.40 & 6.50 & 45.48 & 5.33 & 0.603 \\
\hline Sugars (g/day) & 84.77 & 32.45 & 78.19 & 44.96 & 99.09 & 41.77 & 0.292 & 87.77 & 26.94 & 71.87 & 29.45 & 87.22 & 34.42 & 0.103 \\
\hline$\% \mathrm{TE}$ sugars & 17.88 & 5.18 & 17.20 & 5.92 & 20.97 & 7.54 & 0.139 & 18.74 & 4.70 & 16.13 & 5.69 & 18.30 & 4.96 & 0.126 \\
\hline Free sugars (g/day) & 37.19 & 22.09 & 45.00 & 31.35 & 36.58 & 23.8 & 0.882 & 40.35 & 21.30 & 31.37 & 17.94 & 37.45 & 24.87 & 0.354 \\
\hline$\% \mathrm{TE}$ free sugars & 7.73 & 4.12 & 9.65 & 5.01 & 7.88 & 4.45 & 0.628 & 8.40 & 3.65 & 7.17 & 4.12 & 7.75 & 3.91 & 0.478 \\
\hline Fat (g/day) & 75.91 & 22.64 & 67.94 & 24.71 & 74.32 & 31.07 & 0.644 & 77.97 & 23.49 & 73.93 & 24.20 & 76.99 & 23.37 & 0.812 \\
\hline$\%$ TE fat & 36.02 & 5.52 & 35.20 & 3.70 & 34.13 & 6.11 & 0.479 & 37.07 & 5.57 & 37.01 & 5.58 & 36.25 & 4.77 & 0.690 \\
\hline GI & 57.86 & 5.14 & 59.41 & 5.46 & 57.12 & 5.25 & 0.610 & $55.85^{\mathrm{b}}$ & 4.51 & $59.80^{\mathrm{a}}$ & 4.85 & 57.43 & 4.74 & 0.018 \\
\hline GL & 125.64 & 33.55 & 121.42 & 36.58 & 123.18 & 21.25 & 0.915 & 116.73 & 27.47 & 117.47 & 31.81 & 124.28 & 36.45 & 0.518 \\
\hline
\end{tabular}

Where data are non-normally distributed, they were log transformed for analysis; free sugars (g/day), \% TE free sugars

Significance is set at alpha 0.05 using chi-squared tests for independence for categorical variables and one-way analysis of variance (ANOVA) for continuous variables using post hoc Dunnett's T3 tests for unequal sample sizes

${ }^{1}$ Significance according to Welch's test for equality of means when equal variances are not assumed

Multivariate regression analysis was carried out to examine the association between meal pattern and birth size. Women who followed a snack-dominant pattern were at a lower risk of having an infant with macrosomia compared with those following a large meal-dominant pattern at 28 weeks, controlling for glycaemic index, parity, gestation at birth and sex of the infant (OR 0.39 ; $95 \%$ CI 0.12 $0.98 ; P=0.45)$. On multiple linear regression, controlling for confounds above, large meal-dominant pattern was not significantly associated with birth weight $(\mathrm{g} ; B$, 91.4; 95\% CI, 3.44-186.27; $P=0.59$ ).

\section{Analysis excluding energy under-reporters}

There were 7 participants identified as under-reporters of energy at both 16 and 28 weeks' gestation.

On analysis of normal reporters, at 28 weeks' gestation, the difference in GI between main meal and large meal-dominant patterns was not significant $(P=0.064)$. The main meal-dominant pattern had a significantly higher percentage of energy from sugars compared with the large meal-dominant pattern at 28 weeks' gestation $(19.67 \pm 3.95$ vs. $15.55 \pm 5.31)(P=$ $0.021)$. Birth weight $(\mathrm{kg})$ was not significantly different between meal pattern categories at 28 weeks' gestation $(P=$ 0.092) using Welch's test for significance.

\section{Discussion}

\section{Main findings}

The results presented here provide an insight into meal patterns adopted at two stages of pregnancy among women with a raised BMI and their association with health outcomes. As pregnancy progressed, participants increased the number of eating occasions and snacks consumed per day and reduced the number of main meals consumed. There were few differences in nutrient intakes between those who adopted different meal patterns at both time points; however, the incidence of macrosomia was highest among those with a large meal-dominant pattern at 28 weeks' gestation compared with those with a main mealor snack-dominant pattern at this time point.

The average number of eating occasions of the current study population is similar to general pregnant cohorts reported to date. Those closely following a main meal pattern in the Norwegian Mother and Child Cohort Study (MoBa) at 22 weeks' gestation ate four times per day [20], and roughly one-third of participants in the Growing Up in Singapore Towards Healthy Outcomes study (GUSTO) had an average of four daily eating occasions between 26 and 28 weeks' gestation [22]. Over $70 \%$ of participants in the Pregnancy, Infection and Nutrition Study (PIN) in the US ate on five or more occasions per day during the second trimester [21]. The 
Table 5 Comparison of mean daily nutrient intakes between 16 and 28 weeks' gestation among participants with complete dietary data at both time points $(n=143)$. Mean and SD are presented

\begin{tabular}{|c|c|c|c|c|c|}
\hline & \multicolumn{2}{|c|}{16 weeks $(n=143)$} & \multicolumn{2}{|c|}{28 weeks $(n=143)$} & \multirow[t]{2}{*}{$P$} \\
\hline & Mean & SD & Mean & SD & \\
\hline Energy (kcal/day) & 1872.99 & 419.18 & 1874.11 & 446.57 & 0.978 \\
\hline Protein (g/day) & 79.25 & 19.91 & 81.77 & 20.40 & 0.168 \\
\hline \% TE protein & 17.09 & 3.17 & 17.63 & 3.06 & 0.057 \\
\hline Carbohydrates (g/day) & 216.02 & 52.37 & 211.21 & 54.81 & 0.349 \\
\hline$\%$ TE carbohydrates & 46.34 & 6.11 & 45.17 & 5.50 & 0.031 \\
\hline Sugars (g/day) & 85.71 & 34.13 & 84.62 & 32.98 & 0.740 \\
\hline$\%$ TE sugars & 18.12 & 5.50 & 17.98 & 5.09 & 0.781 \\
\hline Free sugars (g/day) & 37.57 & 22.71 & 36.79 & 23.34 & 0.755 \\
\hline$\% \mathrm{TE}$ free sugars & 7.85 & 4.19 & 7.74 & 3.90 & 0.720 \\
\hline Fat (g/day) & 75.32 & 23.49 & 76.59 & 23.40 & 0.541 \\
\hline$\%$ TE fat & 35.80 & 5.49 & 36.50 & 5.01 & 0.134 \\
\hline Saturated fat (g/day) & 28.01 & 10.24 & 29.49 & 10.39 & 0.121 \\
\hline$\%$ TE SFA & 13.24 & 2.98 & 13.98 & 2.59 & 0.005 \\
\hline Polyunsaturated fat (g/day) & 11.77 & 4.62 & 11.79 & 4.11 & 0.969 \\
\hline \% TE PUFA & 5.64 & 1.76 & 5.66 & 1.52 & 0.896 \\
\hline Monounsaturated fat (g/day) & 27.06 & 9.63 & 26.97 & 9.24 & 0.913 \\
\hline$\%$ TE MUFA & 12.85 & 2.82 & 12.85 & 2.68 & 0.987 \\
\hline Calcium (mg/day) & 918.35 & 330.73 & 959.92 & 346.18 & 0.230 \\
\hline Iron (mg/day) & 12.29 & 5.37 & 11.90 & 3.85 & 0.384 \\
\hline Total folates ( $\mu \mathrm{g} /$ day) & 282.29 & 112.27 & 279.88 & 100.93 & 0.789 \\
\hline Vitamin D ( $\mu \mathrm{g} /$ day) & 3.45 & 2.24 & 3.30 & 2.69 & 0.307 \\
\hline GI & 57.88 & 5.15 & 57.62 & 4.83 & 0.620 \\
\hline GL & 125.18 & 32.63 & 122.04 & 34.51 & 0.331 \\
\hline
\end{tabular}

Where data are non-normally distributed, they were log transformed for analysis; free sugars (g/day), \% TE free sugars, vitamin D

$P$ values were calculated using paired samples $t$ tests for continuous variables

overall number of main meals and snacks consumed as part of these eating occasions were not explicitly reported, however $[20,22]$.

Meal pattern categories observed in the present analysis are also comparable with those reported in the PIN and MoBa cohorts $[20,21]$. In the PIN study, the majority of women (71.5\%) were classed as having a 'regular' meal pattern (3 meals plus 2 or more snacks) [21]. In the MoBa study, women with a BMI in the overweight and obese categories had adhered mostly to an 'evening meal' pattern [20]. Women who were younger or achieved lower levels of education were also more likely to adopt an 'evening meal' pattern [20]. The PIN study reported that women with a higher pre-pregnancy BMI and those who were older were less likely to have a 'regular' meal pattern [21]. In the current study, fewer primiparous women adopted a large meal-dominant pattern in later pregnancy compared with main meal- or snack-dominant patterns.

Those adopting the snack-dominant meal pattern in the current study had a higher number of total eating occasions. There was a higher dietary GI among the large meal-dominant pattern at 28 weeks' gestation. However, there were no differences in reported measures of energy or nutrient intakes between meal pattern categories. The PIN study found that women following a 'regular' meal pattern had significantly higher energy intake than those not following this pattern [21].

Overall mean daily nutrient intakes reported in the current study are similar to those of pregnant women within other studies who are in the same BMI categories [10,34], general pregnant cohorts (where the mean BMI is $26 \mathrm{~kg} / \mathrm{m}^{2}$ ) [11] and non-pregnant adult women [35].

In the MoBa study, women with a BMI $\geq 25 \mathrm{~kg} / \mathrm{m}^{2}$, who showed a higher adherence to a 'main meal' pattern had a reduced risk of delivering a pre-term infant [20]. In the PIN study, those who did not follow a 'regular' meal pattern had a higher risk of delivering a pre-term infant [21]. Contrary to these findings, neither pre-term birth nor gestational age at birth differed between meal patterns in the current study.

No differences were observed in glucose concentrations, insulin resistance or GDM incidence between women who adopted different meal patterns in the current analyses. This 
Table 6 Comparison of maternal and infant outcomes between meal pattern categories at 16 and 28 weeks' gestation among participants with complete dietary data at both time points $(n=143)$. Mean and SD are presented, unless otherwise indicated

\begin{tabular}{|c|c|c|c|c|c|c|c|c|c|c|c|c|c|c|}
\hline & \multicolumn{7}{|c|}{16 weeks' gestation $(n=143)$} & \multicolumn{7}{|c|}{28 weeks' gestation $(n=143)$} \\
\hline & \multicolumn{2}{|c|}{$\begin{array}{l}\text { Main meal }(n= \\
122)\end{array}$} & \multicolumn{2}{|c|}{$\begin{array}{l}\text { Large meal }(n= \\
8)\end{array}$} & \multicolumn{2}{|c|}{ Snack $(n=13)$} & \multirow[t]{2}{*}{$P$} & \multicolumn{2}{|c|}{$\begin{array}{l}\text { Main meal }(n= \\
20)\end{array}$} & \multicolumn{2}{|c|}{$\begin{array}{l}\text { Large meal }(n= \\
25)\end{array}$} & \multicolumn{2}{|c|}{ Snack $(n=98)$} & \multirow[t]{2}{*}{$P$} \\
\hline \multicolumn{13}{|l|}{ Maternal outcomes } & & \\
\hline \multicolumn{15}{|l|}{ Glucose homeostasis } \\
\hline \multicolumn{15}{|l|}{28 weeks } \\
\hline Fasting glucose & 4.45 & 0.38 & 4.49 & 0.31 & 4.52 & 0.48 & 0.825 & 4.46 & 0.31 & 4.51 & 0.32 & 4.44 & 0.41 & 0.758 \\
\hline $1 \mathrm{~h}$ post-prandial & 7.20 & 1.69 & 6.51 & 2.51 & 8.06 & 1.77 & 0.134 & 7.33 & 1.98 & 7.33 & 1.64 & 7.19 & 1.76 & 0.913 \\
\hline $2 \mathrm{~h}$ post-prandial & 5.74 & 1.14 & 5.06 & 1.49 & 6.24 & 1.58 & 0.118 & 5.55 & 1.18 & 6.07 & 1.14 & 5.71 & 1.23 & 0.306 \\
\hline GDM incidence $(n(\%))$ & 12.0 & 10.0 & 0.0 & 0.0 & 2.0 & 16.7 & 0.506 & 2.0 & 10.0 & 1.0 & 4.0 & 11.0 & 11.7 & 0.524 \\
\hline HOMA2-IR & 1.67 & 0.86 & 1.72 & 0.56 & 2.17 & 1.39 & 0.448 & 1.78 & 0.75 & 1.97 & 0.87 & 1.60 & 0.90 & 0.080 \\
\hline \multicolumn{15}{|l|}{ Gestational weight gain } \\
\hline 34 weeks & 10.50 & 4.47 & 6.45 & 4.28 & 11.15 & 5.92 & $0.048^{2}$ & 10.30 & 5.29 & 10.83 & 4.23 & 10.20 & 4.69 & 0.852 \\
\hline Term $^{4}$ & $13.10^{\mathrm{b}}$ & 5.10 & $6.92^{\mathrm{a}, \mathrm{c}}$ & 3.01 & $12.34^{\mathrm{b}}$ & 7.59 & $0.025^{1}$ & 13.37 & 5.37 & 13.23 & 5.44 & 12.31 & 5.50 & 0.711 \\
\hline Exceeded IOM $(n(\%))$ & 57.0 & 72.2 & 0.0 & 0.0 & 5.0 & 55.6 & 0.001 & 11.0 & 73.3 & 14.0 & 87.5 & 37.0 & 58.7 & 0.077 \\
\hline \multicolumn{15}{|l|}{ Infant outcomes } \\
\hline \multicolumn{15}{|l|}{ Gestational age } \\
\hline Gestation (days) & 281.50 & 10.25 & 280.00 & 8.45 & 280.75 & 6.48 & 0.895 & 280.75 & 10.88 & 284.60 & 7.14 & 280.62 & 10.16 & 0.191 \\
\hline Pre-term $(n(\%))$ & 3.0 & 2.5 & 0.0 & 0.0 & 0.0 & 0.0 & 0.773 & 0.0 & 0.0 & 0.0 & 0.0 & 3.0 & 3.2 & 0.480 \\
\hline \multicolumn{15}{|l|}{ Birth weight measures } \\
\hline Birth weight $(\mathrm{kg})$ & 3.70 & 0.54 & 3.47 & 0.70 & 3.63 & 0.25 & $0.550^{3}$ & 3.65 & 0.49 & 3.93 & 0.66 & 3.62 & 0.49 & $0.030^{2}$ \\
\hline Birth weight centile & 49.65 & 27.34 & 35.65 & 28.10 & 44.29 & 21.11 & 0.315 & 49.61 & 21.68 & 54.13 & 29.62 & 46.59 & 27.27 & 0.454 \\
\hline LGA $(n(\%))$ & 11 & 9.2 & 0.0 & 0.0 & 0.0 & 0.0 & 0.366 & 1.0 & 5.0 & 2.0 & 8.0 & 8.0 & 8.5 & 0.870 \\
\hline Macrosomia $(n(\%))$ & 34 & 28.3 & 2.0 & 25.0 & 2.0 & 16.7 & 0.680 & 4.0 & 20.0 & 13.0 & 52.0 & 21.0 & 22.1 & 0.008 \\
\hline
\end{tabular}

Data are mean SD unless otherwise indicated

Where data are non-normally distributed, they were log transformed for analysis; HOMA2-IR

Significance is set at alpha 0.05 using chi-squared tests for independence for categorical variables and one-way analysis of variance (ANOVA) for continuous variables using post hoc Dunnett's T3 tests for unequal sample sizes

${ }^{1}$ Significant ANOVA with significant post hoc analysis (a,b,c denote significance between columns)

${ }^{2}$ Significant ANOVA, however post hoc analysis was not significant

${ }^{3}$ Significance according to Welch's test for equality of means when equal variances are not assumed

${ }^{4}$ Gestational weight gain to term defined as the last recorded weight between 36 weeks' gestation to delivery

is unlike findings from the GUSTO study that found that 2-h post-prandial glucose concentration was positively associated with increasing meal frequency [22]. No published studies to date have examined the relationship between maternal meal patterns and infant birth weight or GWG; thus, this research contributes new insights to this field [36-38]. The finding that women following a large meal-dominant pattern at 28 weeks had infants with greater risk of macrosomia is surprising, particularly since no differences in energy intake was reported. This finding persisted even when controlling for GI, a factor known to be associated with greater birth weight [39], gestation, sex of the infant and parity. A cautious interpretation of the association between GWG and meal pattern at 16 weeks' gestation is warranted given the small sample size $(n=8)$ in the large meal-dominant group.

\section{Interpretation and clinical implications}

It is thought that eating at regular intervals could improve glucose homeostasis among those with diabetes and may aid weight loss or maintenance in overweight and obesity in nonpregnant states $[40,41]$.

Pregnancy is an altered metabolic state, considered diabetogenic, and metabolism may be further influenced by increasing maternal pre-pregnancy BMI which itself has been identified as the main predictor of an array of adverse pregnancy outcomes $[36,38]$. Thus, considering all of the evidence, meal patterns may have a greater impact on health outcomes in population groups such as pregnant women or those with type 2 diabetes where metabolic function has adapted through increases in insulin resistance. 
The majority of participants in this analysis, who received no formal dietary advice, naturally increased the number of eating occasions and migrated towards a snack-dominant meal pattern in later pregnancy. It is possible that this occurred due to the expansion of the uterus and abdomen, compressing the stomach and making larger meals more difficult to finish as pregnancy progressed. Pregnant women should be provided with appropriate dietary advice on healthy, low-GI snacks or light meal options to ensure nutrient intakes are in accordance with current dietary recommendations [42]. We also reported a difference in meal patterns by parity, demonstrating that snacking was more prevalent among those with children at home. It is plausible that snacking may be a more convenient method to meet nutrient intakes in a busy household; however, this association requires further research before conclusions can be drawn.

\section{Strengths}

The current study is the first examining meal patterns in pregnancy to use a food diary for the collection of dietary data; food diaries are considered more precise measurement tools than food frequency questionnaires or 24-h recalls [43]. The current study analysed meal patterns at two time points in pregnancy, whereas others have focused on one time point only [20-22]. To our knowledge, there is no published evidence examining the change in meal patterns as pregnancy progresses.

\section{Limitations}

There is a risk of error with self-reported data due to misreporting [43] which must be considered when interpreting the data. With regard to meal classification, subjective interpretation of what constituted a meal or snack by the nutritionists entering dietary data is a possible limitation. With no global consensus as to what constitutes a snack and how snacks differ from main meals, nor any formal recommendations regarding meal patterns during healthy pregnancies, there is a degree of subjectivity with this type of research. Lastly, these results may not be generalizable across other populations as this sample of women had raised BMI, was predominantly of Caucasian ethnicity and high socioeconomic status. Furthermore, given the number of statistical tests conducted in this study, the possibility of chance findings as a result of multiple testing should be considered. Finally, this was a cohort of women with pre-pregnancy BMI in the overweight and obese categories only; thus, we could not determine if meal patterns were different to women with a healthy BMI. Future research should aim to compare meal patterns across BMI categories as this could lead to greater awareness of dietary behaviours among this group of women.

\section{Conclusion}

This study provides an insight into the meal patterns of women with raised BMI as pregnancy progresses. A migration from main meal-dominant patterns towards a snackdominant meal patterns were observed. Those in the main meal and snack-dominant patterns in later gestation had lower dietary GI intakes, gave birth to infants with lower rates of macrosomia compared with those with a large meal-dominant pattern. These novel findings may inform future dietary recommendations which could benefit both short- and long-term maternal and offspring health.

Acknowledgements The authors wish to thank the study participants and outpatient hospital staff, biostatistician Dr. Ricardo Segurado and database manager Dr. John Meegan.

Funding information This study was funded by The National Maternity Hospital Medical Fund.

\section{Compliance with ethical standards}

Conflict of interest The authors declare that they have no conflicts of interest.

Open Access This article is distributed under the terms of the Creative Commons Attribution 4.0 International License (http:// creativecommons.org/licenses/by/4.0/), which permits unrestricted use, distribution, and reproduction in any medium, provided you give appropriate credit to the original author(s) and the source, provide a link to the Creative Commons license, and indicate if changes were made.

\section{References}

1. Abrams BF, Berman CA (1993) Nutrition during pregnancy and lactation. Prim Care 20:163. https://doi.org/10.1016/S00223182(75)80024-0

2. Health Service Executive. Healthy eating for pregnancy. 2015

3. ministerradet N (2004) Nordic nutrition recommendations 2004: integrating nutrition and physical activity, Copenhagen

4. Food Standards Agency. Eating while you are pregnant: choosing food to keep you and your baby healthy. 2002

5. Evert AB, Boucher JL, Cypress M, Dunbar SA, Franz MJ, MayerDavis EJ, Neumiller JJ, Nwankwo R, Verdi CL, Urbanski P, Yancy WS Jr, American Diabetes Association (2013) Nutrition therapy recommendations for the management of adults with diabetes. Diabetes Care 36(11):3821-3842. https://doi.org/10.2337/dc13-2042

6. Health Service Executive (2010) Guidelines for the management of pre-gestational and gestational diabetes mellitus from preconception to the postnatal period. Changing practice to support service delivery, Dublin http://www.hse.ie/eng/services/ publications/Nursing Midwiferyservices/ onsdguidelinesgestationaldiabetes.pdf. Accessed March 28, 2017

7. NICE (2015) Diabetes in pregnancy: management from preconception to the postnatal period. (February):1-67. 978-1-4731-0993-3

8. Link N (1999) Dietary management of type 2 diabetes mellitus. West J Med 171(July):25-26

9. Silversides CK, Colman JM (2007) Physiological changes in pregnancy. Hear Dis Pregnancy 27(2):89-94. https://doi.org/10.5830/ CVJA-2016-021 
10. Lindsay KL, Heneghan C, McNulty B, Brennan L, McAuliffe FM (2014) Lifestyle and dietary habits of an obese pregnant cohort. Matern Child Health J 19:25-32. https://doi.org/10.1007/s10995-014-1491-2

11. McGowan CA, McAuliffe FM (2012) Maternal dietary patterns and associated nutrient intakes during each trimester of pregnancy. Public Health Nutr 16(April):1-11. https://doi.org/10.1017/S1368980012000997

12. Northstone K, Emmett PM, Rogers I (2008) Dietary patterns in pregnancy and associations with nutrient intakes. Br J Nutr 99(2): 406-415

13. Arkkola T, Uusitalo U, Kronberg-Kippilä C, Männistö S, Virtanen M, Kenward MG, Veijola R, Knip M, Ovaskainen ML, Virtanen SM (2008) Seven distinct dietary patterns identified among pregnant Finnish women-associations with nutrient intake and sociodemographic factors. Public Health Nutr 11(2):176-182

14. Crozier SR, Robinson SM, Borland SE, Inskip HM (2006) Dietary patterns in the Southampton Women's Survey. Eur J Clin Nutr 60(12):1391-1399

15. Crozier SR, Robinson M, Godfrey KM, Cooper C, Inskip HM (2009) Women's dietary patterns change little from before to during pregnancy 1 - 3:6-13. https://doi.org/10.3945/jn.109.109579.scores

16. Moran L, Sui Z, Cramp C, Dodd J (2012) A decrease in diet quality occurs during pregnancy in overweight and obese women which is maintained post-partum. Obes Res Clin Pract 6:84

17. Bodnar LM, Siega-Riz AM (2002) A Diet Quality Index for Pregnancy detects variation in diet and differences by sociodemographic factors. Public Health Nutr 5(6):801-809. https://doi.org/10.1079/PHN2002348

18. Rodríguez-Bernal C, Rebagliato M, Iniguez C et al (2010) Diet quality in early pregnancy and its effects on fetal growth outcomes: the Infancia y Medio Ambiente (Childhood and Environment) Mother and Child Cohort Study in Spain. Am J Clin Nutr 91(5): 1659-1666. https://doi.org/10.3945/ajen.2009.28866. INTRODUCTION

19. Rifas-Shiman SL, Rich-Edwards JW, Kleinman KP, Oken E, Gillman MW (2009) Dietary quality during pregnancy varies by maternal characteristics in Project Viva: a US cohort. J Am Diet Assoc 109(6):10041011. https://doi.org/10.1016/j.jada.2009.03.001

20. Englund-Ogge L, Birgisdottir B, Sengpiel V et al (2017) Meal frequency patterns and glycemic properties of maternal diet in relation to preterm delivery: results from a large prospective cohort study. PLoS One 12(3):no pagination):e0172896. https://doi.org/10.1371/ journal.pone. 0172896

21. Siega-riz AM, Herrmann TS, Savitz DA, Thorp JM (2001) Frequency of eating during pregnancy and its effect on preterm delivery. Am J Epidemiol 153(7):647-652

22. Loy SL, Kok J, Chan Y et al (2017) Maternal circadian eating time and frequency are associated with blood glucose concentrations during pregnancy. 147(1):1-8. https://doi.org/10.3945/jn.116.239392

23. Kennelly MA, Ainscough K, Lindsay K, Gibney E, Mc Carthy M, McAuliffe FM (2016) Pregnancy, exercise and nutrition research study with smart phone app support (Pears): study protocol of a randomized controlled trial. Contemp Clin Trials 46:92-99. https://doi.org/10.1016/j.cct.2015.11.018

24. Kennelly MA, Ainscough K, Lindsay KL, O Sullivan E, Gibney ER, McCarthy M, Segurado R, DeVito G, Maguire O, Smith T, Hatunic M, McAuliffe FM (2018) Pregnancy exercise and nutrition with smartphone application support. Obstet Gynecol 131(5):818826. https://doi.org/10.1097/AOG.0000000000002582

25. Haase T, Pratschke J (2012) The 2011 Pobal HP Deprivation Index for small areas ( SA ) Introduction and Reference Tables. https:// www.pobal.ie/Publications/Documents/IntroductionandReference Tables.pdf

26. Black LJ, Ireland J, Møller A, Roe M, Walton J, Flynn A, Finglas PM, Kiely M (2011) Development of an on-line Irish food composition database for nutrients. J Food Compos Anal 24(7):10171023. https://doi.org/10.1016/j.jfca.2011.01.015
27. Public Health England (2015) McCance and Widdowson's the composition of foods integrated dataset 2015, London www.gov. uk/phe. Accessed April 20, 2017

28. Food Standards Agency (2002) McCance and Widdowson's the composition of foods, 6th summary edn. Royal Society of Chemistry, Cambridge

29. Warde A, Yates L, Warde A, Yates L (2017) Understanding eating events: snacks and meal patterns in great britain. Food Cult Soc 20(1):15-36. https://doi.org/10.1080/15528014.2016.1243763

30. Goldberg G, Black A, Jebb S, Cole TJ, Murgatroyd PR, Coward WA, Prentice AM (1991) Critical evaluation of energy intake data using fundamental principles of energy physiology: 1 . Derivation of cut-off limits to identify under-recording. Eur J Clin Nutr 45(12):569-581

31. McGowan CA, Walsh JM, Byrne J, Curran S, McAuliffe FM (2013) The influence of a low glycemic index dietary intervention on maternal dietary intake, glycemic index and gestational weight gain during pregnancy: a randomized controlled trial. Nutr J 12(1): 140. https://doi.org/10.1186/1475-2891-12-140

32. Henry CJ (2005) Basal metabolic rate studies in humans: measurement and development of new equations. Public Health Nutr 8(7A): 1133-1152. https://doi.org/10.1079/PHN2005801

33. Holman R, Hines G, Kennedy I, Stevens R, Matthews D, Levy J (2004) A calculator for HOMA. Diabetologia. 47(Suppl 1):2004

34. Guelinckx DR, Mullie P, Vansant G (2010) Effect of lifestyle intervention on dietary habits , physical activity, and gestational weight gain in obese pregnant women : a randomized, pp 373-380. https:// doi.org/10.3945/ajen.2009.28166.Am

35. Irish Universities Nutrition Alliance (IUNA) (2011) National adult nutrition survey (NANS) summary report. http://wp-content/uploads/2010/12/National-Adult-Nutrition-Survey-Summary-ReportMarch-2011.pdf

36. Nohr EA, Vaeth M, Baker JL, Sørensen TIA, Olsen J, Rasmussen KM (2008) Combined associations of prepregnancy body mass index and gestational weight gain with the outcome of pregnancy 1-3

37. Reichetzeder C, Dwi Putra SE, Li J, Hocher B (2016) Developmental origins of disease - crisis precipitates change. Cell Physiol Biochem 39(3):919-938. https://doi.org/10.1159/000447801

38. Nelson SM, Matthews P, Poston L (2012) Maternal metabolism and obesity: modifiable determinants of pregnancy outcome. Hum Reprod Update 16(3):255-275. https://doi.org/10.1093/humupd/dmp050

39. McGowan CA, McAuliffe FM (2010) The influence of maternal glycaemia and dietary glycaemic index on pregnancy outcome in healthy mothers. Br J Nutr 104:153-159. https://doi.org/10.1017/ S0007114510000425

40. Kulovitz MG, Ph D, Kravitz LR et al (2014) Potential role of meal frequency as a strategy for weight loss and health in overweight or obese adults. Nutrition. 30(4):386-392. https://doi.org/10.1016/j. nut.2013.08.009

41. Farshchi HR, Taylor MA, Macdonald IA (2005) Beneficial metabolic effects of regular meal frequency on dietary thermogenesis, insulin sensitivity, and fasting lipid profiles in healthy obese women. Am J Clin Nutr 81(1):16-24

42. SACN (2015) Carbohydrates and health

43. Ortega RM, Perez-Rodrigo C, Lopez-Sobaler AM (2015) Dietary assessment methods: dietary records. Spanish J Community Nutr. https://doi.org/10.3305/nh.2015.31.sup3.8749

44. IADPSG (2010) International Association of Diabetes and Pregnancy Study Groups Recommendations on the Diagnosis and Classification of Hyperglycaemia in Pregancy. Diabetes Care 33(3):676-682

Publisher's note Springer Nature remains neutral with regard to jurisdictional claims in published maps and institutional affiliations. 